\title{
MULHERES MIGRANTES NA FRONTEIRA BRASIL-BOLÍVIA
}

\author{
Roberta Guimarães Peres* \\ Rosana Baeninger**
}

migraçào internacional recente em território brasileiro já se apresenta como um fenòmeno relevante, complexo e multifacetado da populaçào há mais de $5($ anos, em especial nas áreas de fronteiras. Os fluxos migratórios chamam a atenção pela complexidade e volume da circulação de pessoas e capitais, bem como pelos impactos nos espaços mig̣atórios; diversos não somente em pontos de origem e destino, mas tambèm em motivaçōes, trajetórias e estratégias.

A fronteira Brasil-Bolívia abriga um movimento intenso entre os dois paises, em ondas migratórias de diferentes intensidades (Silval, 1997). Neste contexilo, surge o tema da migraçiâo femininal e seus diferenciais em todos os aspectos do fenomeno. Baseado numa pescluisa de campo realizada em Corumbá no fim de 2006, em parceria entre o NEPO (Núcleo de Estudos de Populacioo) e o IRD (Institut de Recherche pour le Développement) França, este artigo se propõe a um olhar atencioso sobre as mulheres envolvidas neste fluxo migratório.

A perspectiva de gènero torna-se importante aporte teórico das migralçoes internacionais, porcue revela questies latentes que por muito tempo foram cleixadas de lado em funçào de análise voltada exclusivamente para os aspectos economicos da migração internacional (Morokvalsic, 2003; Boyd e Grieco, 2003). O migrante era definido como do sexo masculino, sem cjue se questionasse a presença das mulheres em tluxos migratórios, e seus diferen- ciais e impactos causidos pelo volume de mulheres que circulavam em espaços migratórios que eram definidos a principio como masculinos (Morokvasic, 2003).

Neste sentido, relaçòes de gênero construidas desde o lugar de origem dos migrantes a ao longo de lodo o processo, delimitam, condicionam, configuram e orientam esses fluxos, através de diferentes vetores, tanto femininos como masculinos, tanto em relaçôes familiares quanto na inserção dos migrantes em seus lugares de destino.

\section{CORUMBÁ-MS: AS ESPECIFICIDADES DE UM LUGAR RECEPTOR DE MIGRANTES NA FRONTEIRA}

Domenach (1996, p. 17) define em linhas gerais a configuração do contexto migratório atual no Mercosul: "En el MERCOSUL. Io cicroro es que la movilidad var e'n aumento. y los movimientos de población estion siendo muny flexibles, mientras que las estadisticas oficiales persisten en subestimar los datos reales pues hacen referencia a una des/inición restrictiva de la migración. hasada solamente en el cambio de residencia. Asistimos a unna intensa recomposición de los territérios y de sus costumbres. Io que tiene fivertes incidencias en materia migratoria puester que los hombres dependen cada vez más de loss mecanismes ste produccion ".

A "intensa recomposiçào dos territórios e de seus costumes" parece estar diretamente ligada à história migratória da América Latina, já que o) fluxo Bolivia - Argentina de que trata
Domenach (1996) e também o lluxo Bolivia-Brasil sãodinâmicose a a longo de suas histórias se estenderam por lugares especificos de origem e destino, de modo a transformar os espaços em diferentes dimensões - sociais. demográficals, econômicas.

No casso especifico do lluxo Bolívia - Brasil, Corumbá/Mato Cirosso do Sul. reúne em si algumas características importantes que a lazem uma cidade chave na análise das trocas migratórias nesta fronteira. Segundo (Oliveira(1998), "Corumbá é diferente por sua história. por sua geografia e por sua economia". Num estudo comparativo entre cidales do Mato Grosso do Sul, Oliveira (1908) enumera múltiplas razōes que diferenciam Cormmba e lhe atribuem especificidades que justificam sua condição de receptora de migrantes num fluxo que comporta correntes migraltórias diferentes ao longo de $5($ ) anos.

Há outra particularidade da cidade de Corumbá no que se refere ao seu papel no fluxo migratório de bolivianos. Localizada a $403 \mathrm{~km}$ de Campo Grande, capital do Mato Grosso do Sul, e a apenas $5 \mathrm{~km}$ de Puerto Quijarro - cidade fronteiriça boliviana, Corumbá mantém relaçōes econômicas muito mais estreitas com a Bolivia do yue como Brasil (Oliveira, 1998). Esse é um tralço que irá, ao longo da história migratória desta fronteira, alimentar em diferentes intensidades ondas de migrantes bolivianos. Essa proximidade - óbvia se pensarmos que se tratia de região de fronteira, mas muito complexal se nos aprofundarmos nas relaçōes intraregionais - também se refletirá nos 
processos migratórios como veremos adiante, na análise de trajetórias. Os migrantes bolivianos, antes de atravessarem a fronteira com o Brasil, protagonizam intensa migração interna na Bolívia. Isso também aponta para o fato de Corumbá/MS poder ser considerada etapa de um processo migratório essencialmente boliviano, e não brasileiro (Souchaud e Baeninger, 2008).

Uma consideração se faz importante: "contempla-se a migração internacional nas áreas de fronteiras como uma migração de vizinhança: fenômeno essencialmente local, onde a fronteira e seus moradores são considerados isolados das dinâmicas continentais" (Souchaud e Baeninger, 2008, p. 14). Ainda que os $200 \mathrm{~km}$ de fronteira Corumbá/MS com a Bolívia possam ser considerados isolados da dinâmica do próprio Mato Grosso do Sul, o papel de Corumbá na dinâmica migratória boliviana a coloca numa outra posição que não a "migração de vizinhança" tão comum em áreas fronteiriças.

Por fím, além dessa relação estreita com processos econômicos e do importante papel na dinâmica migratória da Bolivia, Corumbá apresenta ainda outra especificidade: "a cidade é um lugar estratégico de articulação dos fluxos de bens, pessoas e informações, configurando o denominado corredor bi-oceânico. Esse corredor agrega as duas margens litorâneas do continente, isto é, o sudeste brasileiro com os portos peruanos e chilenos do Pacífico, passando pelo eixo de concentração do povoamento boliviano Santa Cruz Cochabamba - La Paz" (Souchaud e Baeninger, 2008, p. 5).

Dessa perspectiva, se diferencia a migração na fronteira Corumbá/MS com a Bolívia do caso dos brasiguaios, por exemplo, ou ainda de outros fluxos migratórios internacionais brasileiros, caracterizados por grandes distâncias. Para aprofundarmos a análise desse fenômeno, partiremos da questão da migração feminina, suas implicações, impactos e novas explicações no âmbito da migração internacional.

\section{GÊNERO E MIGRAÇÃO INTERNACIONAL: UMA CONSTRUÇÃO SOCIAL}

Segundo Boyd e Grieco (2003), gradualmente, o gênero visto como variável foi aparecendo em um número cada vez maior de pesquisas. Não se questionava, no entanto, os modelos utilizados para explicar por que as pessoas migravam, para onde foram, como se integraram à sociedade receptora. Há diferenças entre hemens e mulheres em todas essas dimensões, bem como papéis específicos, que o gênero visto como "variável" não explica.

As teorias feministas, ao longo dos anos 90 , contribuíram pressionando por trazer o gênero ao primeiro plano das análises migratórias. A principal contribuição deste período foi o esclarecimento do gênero como socialmente construido, dinâmico e raiz de comportamentos, relações hierárquicas de poder, cultura, identidades (Boyd e Grieco, 2003; Pessar, 2003). Dessa forma, era superada a perspectiva de decisões individuais de migrar:essencialmente do sexo masculino-e, posteriormente, da teoria compensatória que incorporava mulheres nos movimentos migratórios sem que se pudesse chamar essa análise de gendering migration (migração de gênero). Isso porque, ao longo deste período, a preocupação maior dos pesquisadores era justamente compensar essa invisibilidade das mulheres em fluxos migratórios através de estudos de caso que se preocuparam apenas com o comportamento das mulheres ao longo da migração. Esse tipo de análise é pré-requisito para a construção de uma perspectiva de gênero (Harzig, 2003). No entanto, as relações de gênero socialmente construidas não eram explicadas por essa perspectiva teórica.
Outro importante aspecto da teoria feminista que contribuiu para a construção de uma perspectiva analitica da migração através do gênero é de que essa "construção social" - que se constitui em expressões de masculinidade e feminilidade e suas relações entre si variam entre as sociedades. Desta forma, ao longo de um movimento migratório, as relações de gênero socialmente construídas se reafirmam ou se transformam, o que significa que ao mesmo tempo elas se constroem e se reconstroem socialmente através do tempo e do espaço (Boyd e Grieco, 2003).

Em especial no fluxo existente na fronteira Brasil - Bolívia, na cidade de Corumbá, a questão do gênero se faz fundamental: os diferenciais por sexo são latentes desde o planejamento migratório e as estratégias utilizadas. Os impactos desses diferenciais apontam para transformações no âmbito das familias migrantes e na configuração do próprio fluxo já nos resultados preliminares da pesquisa realizada em Corumbá/MS

\section{A PESQUiSA DE CAMPO EM CORUMBÁ/MS ${ }^{1}$}

A partir da seleção de domicilios onde pelo menos um dos chefes fosse nascido na Bolivia, foram levantados dados sobre as condições de moradia e a caracterização sócio-demográfica dos residentes desses domicílios, tendo como foco principal a reconstrução das trajetórias desses migrantes, em âmbito individual e relacionado a redes sociais de parentesco e amizade. Desta forma, o questionário foi aplicado a 215 domi- cílios, de acordo com o método "bola de neve".

No caso da ENCOR (Encuesta Corumbá), procurou-se traçar um perfil consistente desses migrantes bolivianos, bem como de suas trajetórias, a fim de entender o papel de Corumbá/MS nesse fluxo migratório, as relações que os migrantes mantêm com este espaço definido e com outros que surgiram a 
partir dos resultados da pesquisa (Souchaud e Fusco, 2007).

Uma especificidade do questionário da ENCOR era um módulo exclusivo para os bolivianos: a reconstrução do maior número de etapas migratórias antes da chegada a Corumbá/MS acabou revelando uma migração interna muito intensa na Bolívia, antes da travessia da fronteira rumo ao Brasil (Souchaud e Fusco, 2007). Daí pode-se detectar a presença de ondas migratórias diversas, que variaram no tempo e nos espaços de origem e destino em 50 anos de fluxo.

Algumas particularidades da pesquisa, no entanto, devem ser ressaltadas, principalmente se inseridas no âmbito da análise de gênero: a possibilidade de dissociação dos dados, a reconstrução das trajetórias migratórias de homens e mulheres, as informações sobre estratégias para migrar e o uso diferenciado de redes sociais são campos importantes de investigação sobre os diferenciais por sexo na migração, que não podem ser captados em outras fontes como os censos demográficos, por exemplo.

Os resultados apresentados a seguir se referem justamente a estas particularidades mencionadas acima, tão valiosas para estudos de migração feminina.

\section{OS PRIMEIROS RESULTADOS DA ENCUESTA CORUMBÁ}

Apresentaremos, então, um perfil sócio-demográfico geral das mulheres bolivianas em Corumbá, suas trajetórias migratórias e as estratégias utilizadas por elas desde o planejamento da viagem, até os primeiros contatos no destino. $\mathrm{O}$ Gráfico l mostra as mulheres entrevistadas na pesquisa, segundo grupos etários e nacionalidade brasileira e boliviana.

Foram levantadas informações sobre 1.157 mulheres $^{2}$, sendo que destas, 676 são bolivianas, 470 são brasileiras e as 12 restantes são de outros países da América Latina. Para melhor visualização desses dados, levaremos em conta apenas os dados sobre bolivianos e brasileiros.

De acordo com o Gráfico 1, notamos uma distribuição maior entre as mulheres bolivianas ao longo dos grupos etários. Uma questão muito importante é a segunda geração de migrantes: vale lembrar que as mulheres brasileiras entrevistadas nesta pesquisa de campo residem em domicílios onde pelo menos um dos chefes é boliviano. Ora, se é assim, fica clara então a onda da formação de uma segunda geração de

\section{Gráfico 1:}

Distribuição das mulheres bolivianas e brasileiras segundo grupos etários

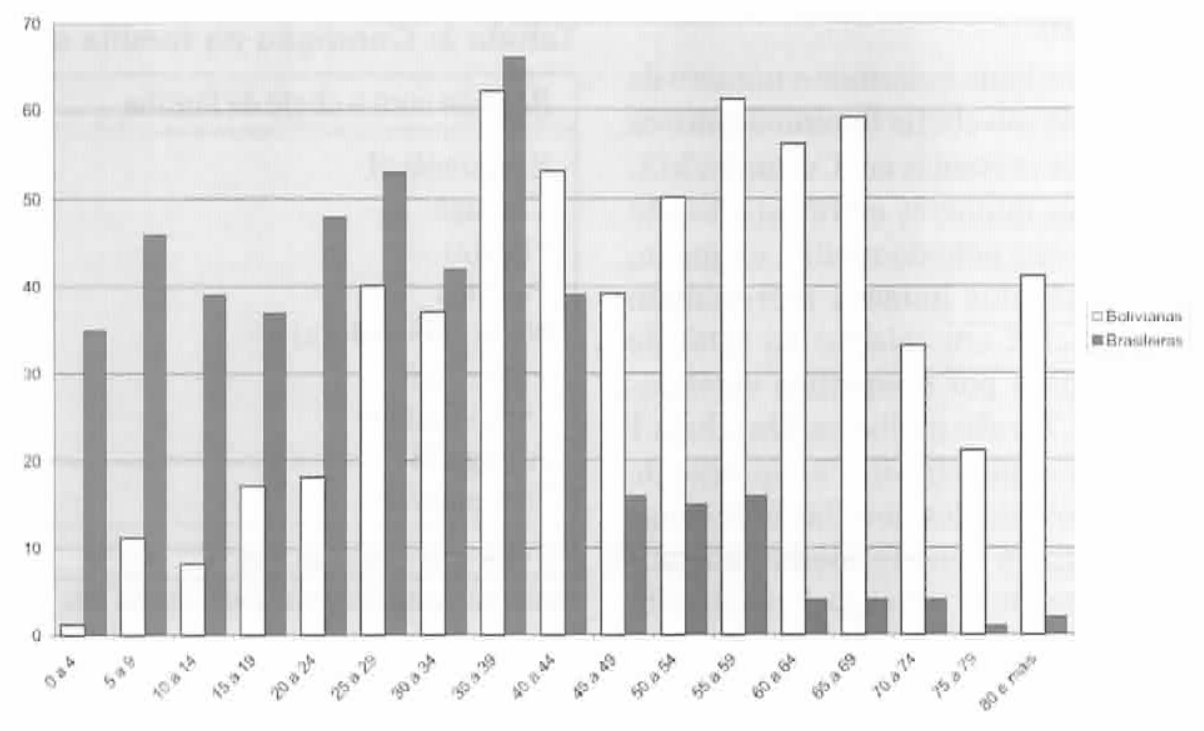

Gráfico 2: Periodo de chegada dos bolivianos a Corumbá - MS

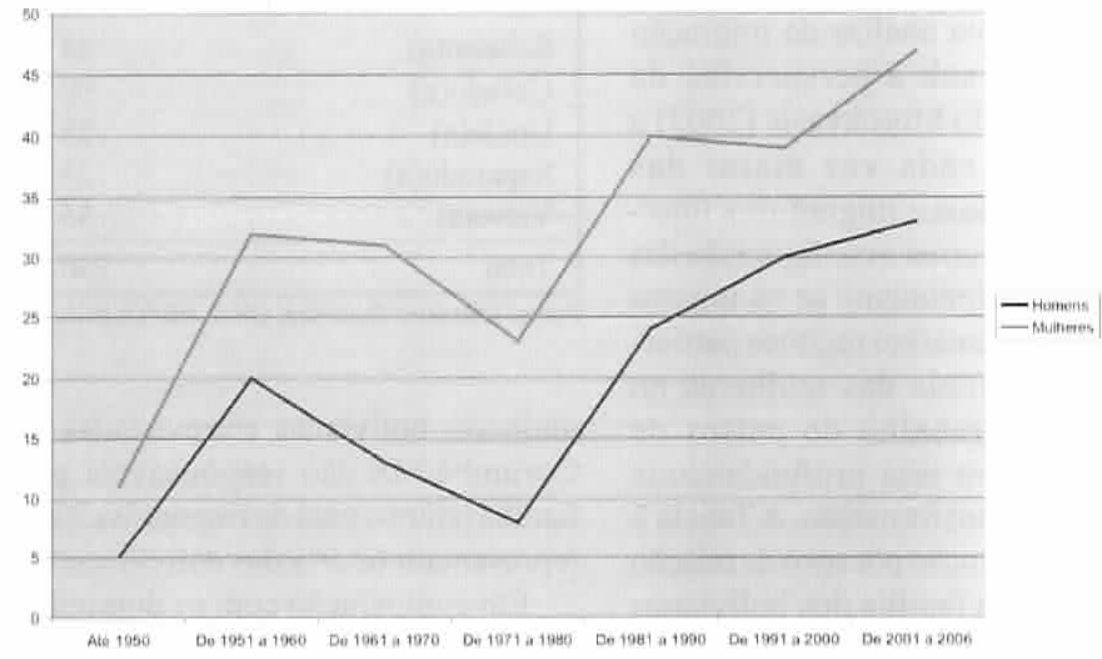

Fonte: Encuesta Corumbá, 2006. NEPO/ IRD. migrantes, filhos das mulheres bolivianas com mais de 50 anos que, se nascidos no Brasil, são brasileiros. O Gráfico 2 apresenta o período de chegada a Corumbá/MS dos bolivianos captados pela pesquisa.

A migração feminina sofre queda muito mais acentuada nos anos 1970, mas recupera-se ainda na mesma década e experimenta um incremento acentuado ao longo da década de 1980, para voltar a crescer no fim dos anos 1990. A variação do padrão masculino é mais 
suave, mas ainda assim, dinâmica e em ascensão.

Uma das questões mais relevantes para análise da migração feminina são os papéis de gênero de cada um dos residentes no domicilio. Dessa forma, a condição na família e no domicílio são variáveis fundamentais para os diferenciais por sexo ao longo da trajetória migratória. A (re)configuração familiar tem um papel fundamental ao apontar transformações em relações de poder e gênero nas esferas privadas (âmbito domiciliar e familiar) e públicas (referentes principalmente à entrada da mulher no mercado de trabalho do país de destino).

É importante notarmos o número de domicilios sob chefia feminina entre os bolivianos presentes em Corumbá/MS: $58,3 \%$ das mulheres entrevistadas são responsáveis pelo domicílio, enquanto que $54,5 \%$ dos homens representam este papel. Com relação ao total de responsáveis por domicilios entrevistados, $64,7 \%$ são mulheres. Da tabela 1 podemos ainda elaborar a hipótese de que a tipologia das famílias bolivianas em Corumbá será formada substancialmente pelo arranjo "casal com filhos", já que outras relações com o responsável apresentam frequências muito baixas.

O papel das mulheres frente à chefia das famílias também é elemento fundamental para uma análise da migração internacional sob a perspectiva de gênero. Segundo Morokvasic (2003) a participação cada vez maior das mulheres em fluxos migratórios internacionais transforma a configuração das famílias, principalmente se os lugares de origem sustentarem regimes patriarcalistas. A entrada das mulheres no mercado de trabalho de países de destino também está profundamente ligada a essa transformação. A Tabela 2 mostra a distribuição por sexo da relação com o chefe da família dos bolivianos em Corumbá; reforça os dados vistos anteriormente na Tabela 1: $60,0 \%$ das

Tabela 1: Condição no domicilio segundo o sexo.

\begin{tabular}{|lccr|}
\hline Relação com o chefe do domicilio & Masculino & Feminino & Total \\
\hline Responsável & 73 & 134 & 207 \\
Cônjuge & 24 & 48 & 72 \\
Filho(a) & 23 & 27 & 50 \\
Pai/Mãe & 0 & 1 & 1 \\
Neto(a)/bisneto(a) & 1 & 0 & 1 \\
Irmão/irmã & 5 & 8 & 13 \\
Outro parente & 6 & 6 & 12 \\
Agregado & 0 & 1 & 1 \\
Não parente & 2. & 5 & 7 \\
\hline Total & 134 & 230 & 364 \\
\hline
\end{tabular}

Fonte: Encuesta Corumbá, 2006. NEPO/ IRD.

Tabela 2: Condição na família segundo o sexo.

\begin{tabular}{|lccr|}
\hline Relação com o chefe da família & Masculino & Feminino & Total \\
\hline Responsável & 78 & 138 & 216 \\
Cônjuge & 23 & 50 & 73 \\
Filho(a) & 21 & 28 & 49 \\
Pai/Mãe & 0 & 1 & 1 \\
Neto(a)/bisneto(a) & 1 & 0 & 1 \\
Irmão/irmã & 5 & 7 & 12 \\
Outro parente & 5 & 1 & 6 \\
Agregado & 0 & 1 & 1 \\
Não parente & 1 & 4 & 5 \\
\hline Total & 134 & 230 & 364 \\
\hline
\end{tabular}

Fonte: Encuesta Corumbá, 2006، NEPO/ IRD.

Tabela 3: Status conjugal das mulheres, segundo país de nascimento.

\begin{tabular}{|lcrr|}
\hline Estado conjugal & Bolívia & Brasil & Total \\
\hline & $\mathrm{N}$ & $\mathrm{N}$ & $\mathrm{N}$ \\
Solteiro(a) & 44 & 139 & 183 \\
Casado(a) & 90 & 27 & 118 \\
Unido(a) & 28 & 14 & 42 \\
Separado(a) & 23 & 10 & 33 \\
Viúvo(a) & 35 & 6 & 41 \\
\hline Total & 230 & 276 & 508 \\
\hline
\end{tabular}

Fonte: Encuesta Corumbá, 2006. NEPO/ IRD.

mulheres bolivianas entrevistadas em Corumbá/MS são responsáveis pela familia (entre o total de responsáveis elas representam $63,9 \%$ das entrevistas).

Em comparação com os domicílios sem a presença boliviana que foram entrevistados na pesquisa de campo, a proporção de chefia da família entre as mulheres é de $10,1 \%$. No entanto, é preciso atentar às informações do Gráfico 1, visto anteriormente, que mostra que a maior parte das brasileiras entrevistadas estava concentrada em grupos etários mais jovens, tendo peso 
proporcional maior, sobretudo entre as fillhas de responsáveis pelos domicílios e famílias.

No contexto da configuração familiar, o estado conjugal dos migrantes também tem grande importância para a análise de transformações de relações de gênero e papéis de cada indivíduo na hierarquia doméstica. De acordo com os dados da pesquisa de campo, as mulheres bolivianas e brasileiras têm o status conjugal revelado na Tabela 3 .

Observa-se que 19,1\% das mulheres bolivianas entrevistadas em Corumbá são solteiras, enquanto que $51,3 \%$ são casadas ou se encontram em uniões estáveis. O quadro entre as brasileiras carrega o diferencial de idade visto anteriormente: as mulheres brasileiras entrevistadas têm idade média inferior que as bolivianas (21 e 44 anos, respectivamente).

De acordo com os dados, $67,4 \%$ dessas mulheres que se encontram casadas ou em uniões estáveis atingiram esse estado conjugal no Brasil, após a chegada a Corumbá. Com esse dado fica descartada a possibilidade do alto número de mulheres neste fluxo migratório impulsionado por questões ligadas à reconfiguração familiar, ou simplesmente da mulher num papel secundário de acompanhante.

$\mathrm{Um}$ dos principais vetores que diferenciam homens e mulheres ao longo de trajetórias migratórias são as estratégias utilizadas para a realização da migração, o que inclui a relação com os lugares que compõem o fluxo, a utilização desses espaços como recursos migratórios e ainda a relação do uso desses recursos com o ciclo de vida dos migrantes.

Como mencionado anteriormente, $o$ movimento de migração interna pelo qual passam os migrantes bolivianos antes de atravessarem a fronteira é elemento constituinte do processo migratório que atravessa o limite nacional (Souchaud e Baeninger, 2008). O Mapa 1 mostra as mulheres bolivianas
Mapa 1: Mulheres bolivianas residentes em Corumbá, em 3 etapas migratórias anteriores.

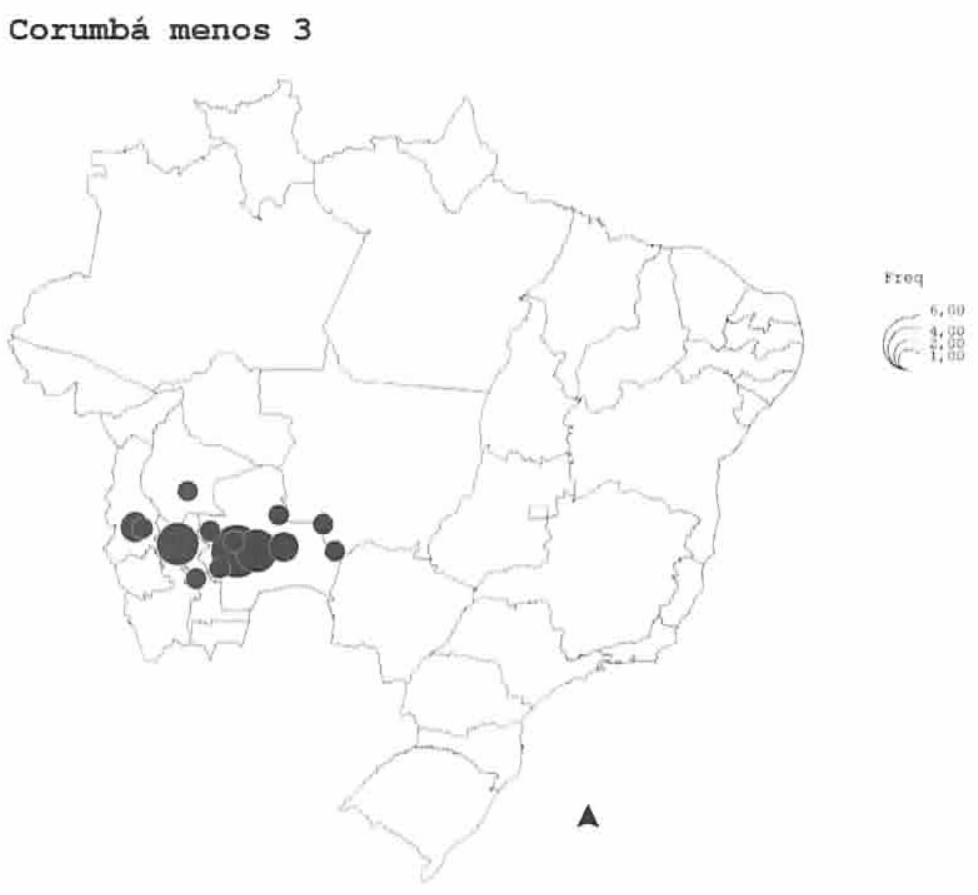

Mapa 2: Mulheres bolivianas residentes em Corumbá, em 2 etapas migratórias anteriores.

Corumbá menos 2

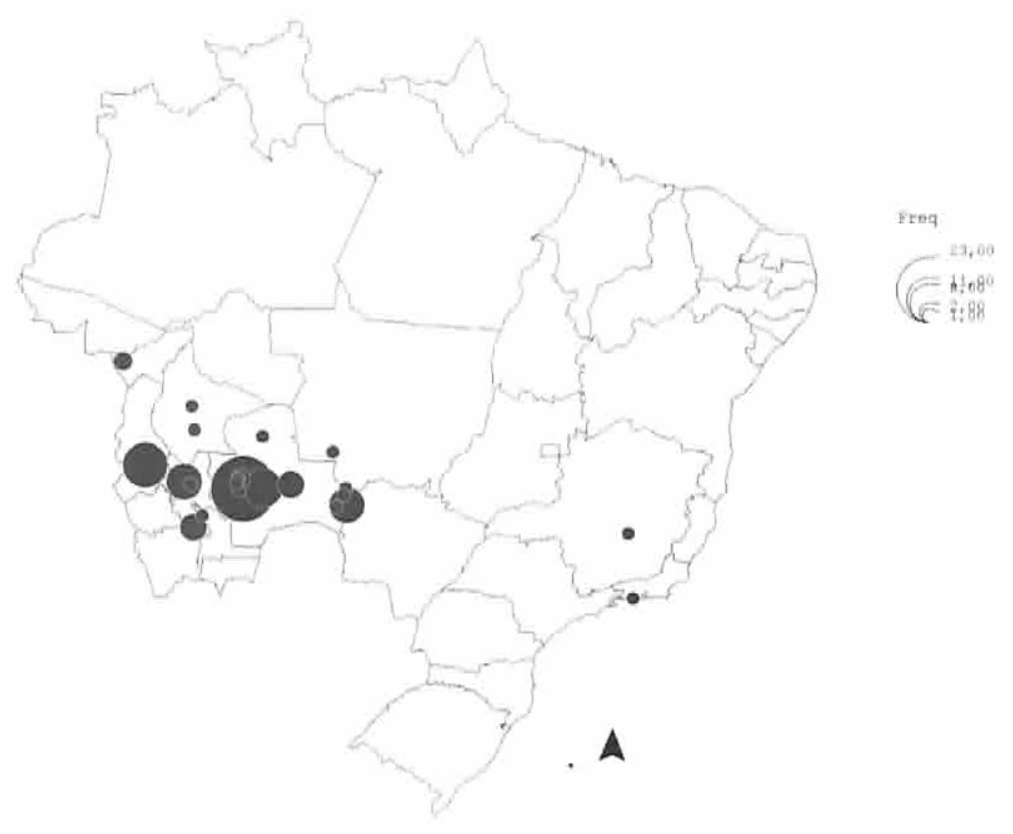

Fonte: Encuesta Corumbá, 2006. NEPO/IRD. 
que residiam em Corumbá no momento da pesquisa em 3 etapas migratórias anteriores.

Uma das particularidades do questionário aplicado em Corumbá/MS está relacionado justamente às trajetórias: um histórico era recomposto pelo entrevistado no sentido inverso do próprio fluxo. Desta forma, partindo da chegada a Corumbá, os bolivianos iam recompondo suas trajetórias, etapa por etapa, da mais recente à mais antiga.

Assim chegamos às trajetórias reconstruidas desses migrantes: a forte migração interna antes do cruzamento da fronteira rumo a Corumbá verificada para a população migrante em seu conjunto (Souchaud e Baeninger, 2008) também ocorre para as mulheres. No Mapa 1 vemos que há, à exceção de duas concentrações em Santa Cruz e La $\mathrm{Paz}$, uma dispersão relativamente longe da frontcira com o Brasil, espalhadas por vários departamentos bolivianos.

À medida que as etapas migratórias vão avançando, uma espécie de eixo é formado em direção à fronteira com $o$ Brasil e, mais adiante, em direção a Corumbá. O Mapa 2 mostra as mesmas migrantes duas etapas antes de chegarem a Corumbá.

É importante ressaltar que a cada etapa migratória aumenta o volume de mulheres, já que nem todas cumpriram o mesmo número de etapas. Assim, podemos observar no mapa 2 uma concentração maior na fronteira, e, ao longo dos departamentos, uma certa convergência de outros polos que se formaram, bem como a presença, ainda que num volume muito baixo, de migrantes bolivianos, a duas etapas da chegada a Corumbá, já em território brasileiro: em Minas Gerais e Rio de Janeiro. O Mapa 3 mostra a última etapa antes da chegada a Corumbá.

Uma possibilidade de análise das trajetórias permitida pelo banco de dados é a separação das etapas migratórias e do lugar de nascimento. Assim, estão ilustradas no Mapa 3 apenas as mulheres

\section{Mapa 3: Mulheres bolivianas residentes em Corumbá, em uma etapa migratória anterior.}

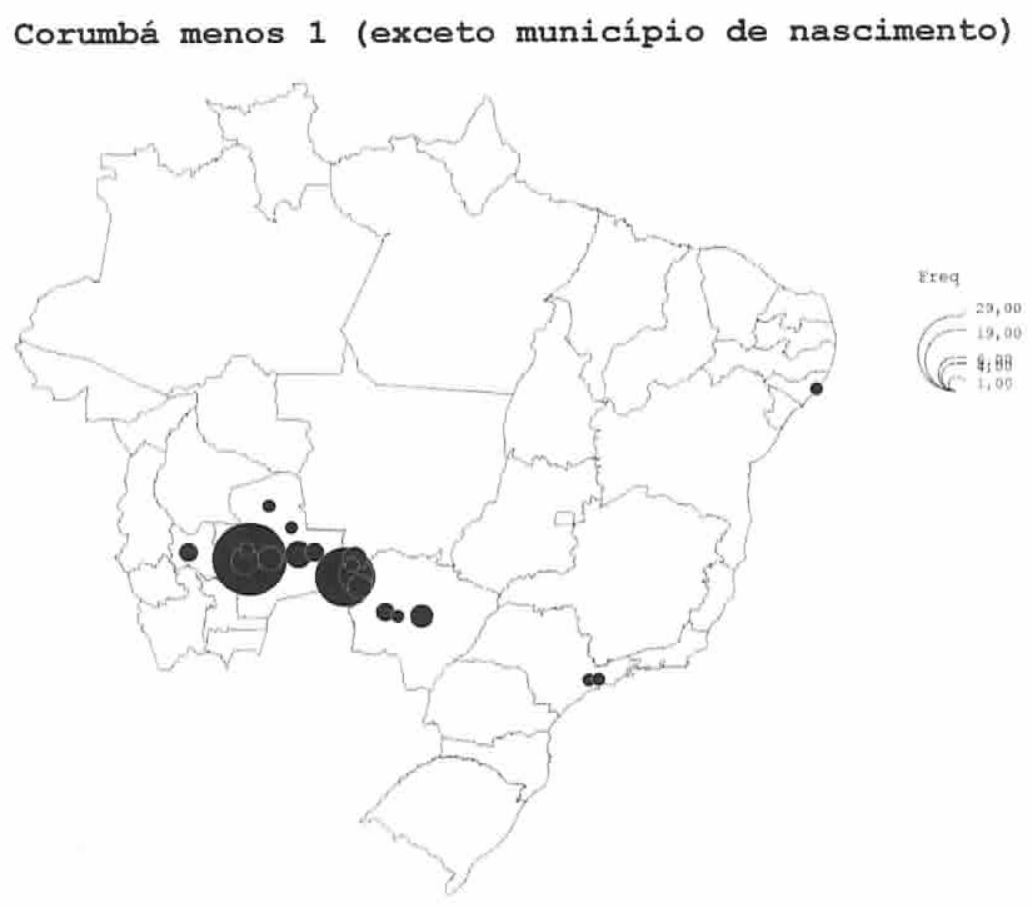

Mapa 4: Mulheres bolivianas residentes em Corumbá, segundo lugar de nascimento como única etapa migratória.

Município de Nascimento para Corumbá

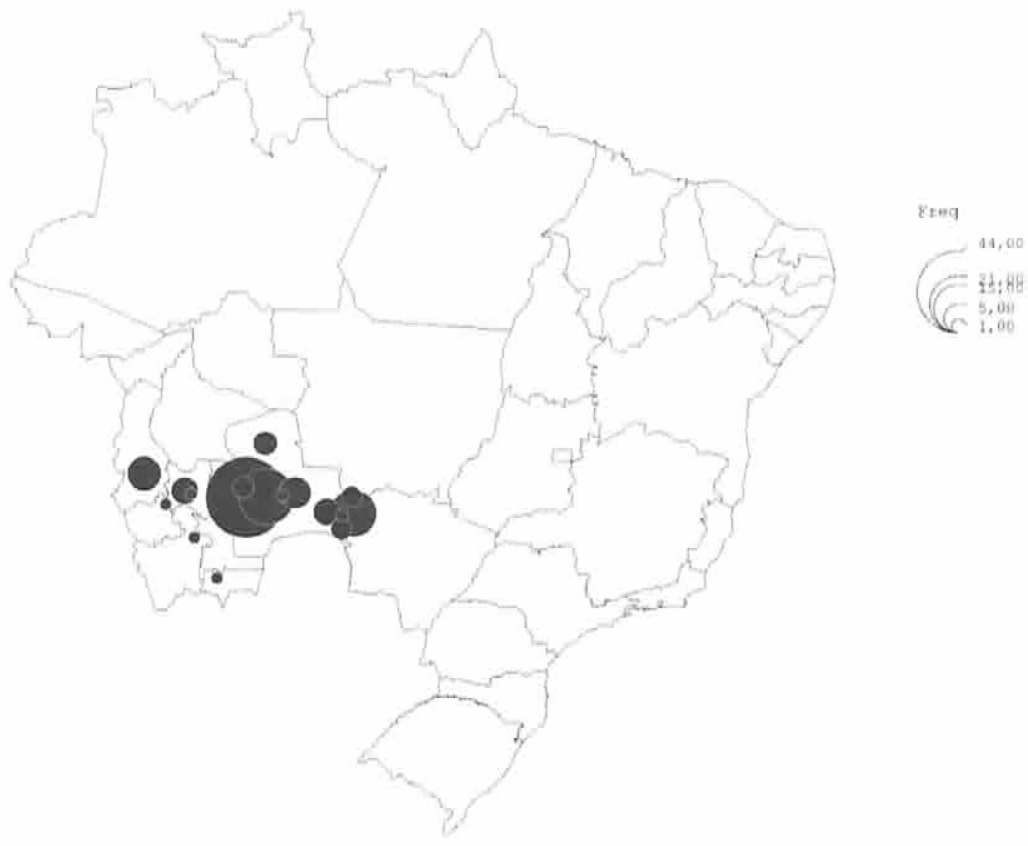

Fonte: Encuesta Corumbá, 2006. NEPO/ IRD. 
que passaram por uma etapa migratória antes de chegar a Corumba/MS. Ou seja: elas passaram por esta etapa antes de chegarem ao destino tinal (no momento da pesyuisa de campo).

Outros polos de concentração surgem à medida em que a trajetória vai chegando ao final. Há um numero maior de pessoas já concentradas em cidades fronteiriças, como Puerto Quijarro e Puerto Suarez e, ao mesmo tempo, a dispersão entre os departamentos bolivianos diminui.

Finalmente, o Mapal 4 mostra as migrantes que sairam do lugar de mascimento e, sem passar por qualquer etapa anterior, migraram para Corumbá/MS.

Entre as mulheres bolivianas que não cumpriram outra etapa migratória que o próprio lugar de nascimento, a distribuição é a esperada: concentração em lugares como Santa Cruz e La Paz, e lambém já na região de fronteira, afastando assim esse grupo da intensa migração intema em território boliviano antes da chegada a Corumbá.

\section{CONSIDERAÇŌES FINAIS}

Dado que a presença feminina boliviana em Corumbá/MS se apresenta com importância histórica relevante ao Iongo do século XX, a cuestão do gênero na migração surge como importante perspectiva de análise. O fato de mulheres bolivianas serem maioria num fluxo migratório na fronteira entre dois paises aponta para diversas especificidades deste processo, que só poderão ser analisadas levando em consideração diferenciais por sexo e as transformaçòes em relações de gênero ao longo da migração.

Desta forma, Morokvasic (20)3) chama a atenção para importantes questōes, como as diferentes estratégias e trajetórias migratórias de homens e mulheres. Ao mesmo tempo, diferenças em processos (le inserção na socieclade de destino revelam mercados especilicos de homens e mulheres bolivianos em Corumbá, profundamente ligados à cultura boliviana de divisão sexual do trabalho (Allen, 1981). A tradição economica comercial corumbaense acaba criando vínculos com a inserção das mulheres em mercados de trabalho especificos, sobretudo em feiras.

A questão das transformações nas relações de gênero também é marcuante no fluxo de bolivianos para Corumbá. O empoderamento feminino, o ganno de autonomia na gestão de recursos familiares, o incremento do poder de decisão na familia, são características das mulheres bolivianas envolvidas neste flux() migratório.

É importante destacar ainda a importância de aspectos e tradiçōes bolivianas nas especificidades deste fluxo migratório. As estratégias e trajetórias migratórias das mullheres são construidas através de relaçòes rituais de parentesco, como o apadrinhamento. O comércio na Bolivia - culturalmente menos valorizado - é atividade fèminina. O trabalho no campo, este sim, muito valorizado nas culturas quéchua e aymara, é tradicionalmente trabalho de homens (Allen, 1981). Ao cruzar a fronteira, essas relações sofrem abalos, uma vez que o comércio é a principal atividade da região, que, por seus aspectos naturais, tem dificultada a produção agrícola. Reconfiguração de relações de gênero na familia, empoderamento feminino, cultura e tradição, diferenciais de sexo ao longo do projeto migratório, são questões que devem ser levadas em conta para compreender o fluxo de bolivianos no Brasil e especialmente em Corumbá, uma fronteira de dinâmica própria.

\footnotetext{
* Roberta Guimarāes Peres é Doutoranda em Demografia pela Universidade Estadual de Campinas - IFCH/NEPO.

* Rosana Baeninger é do Departaricento de Demografia IFCH e Coordenadora do Núcleo de Estudos de Populaçāo - NEPO/ UNICAMP.
}

\section{NOTAS}

1 - Inserida num amplo projeto de pesquisa intitulado "Espaços migratórios e a problemática ambiental no MERCOSUL" em parceria entre o NEPO e o IRD-França, a pesquisa ENCOR (Encuesta Corumbà) foi realizada no municipio em outubro de 2006. com o objetivo principal de (re)construir o espaço migratório existente na fronteira entre Brasil e Bolivia naquela regiāo, sob a coordenaçāo de Sylvain Souchaud e Wilson Fusco.

2 - Incluindo-se as nāo-residentes.

\section{REFERÉNCIAS BIBLIOGRÁFICAS}

ALLEN, C. J.

(1981) "Be a quéchua". In: American Ethnologist, vol. 8, $n^{\circ} 1$. Blackwell Publishing on behalf of the American Anthropological Association. Washington.

BOYD, M. e GRIECO, E.

(2003) Women and Migration: Incorporationg gender into international migration theory. Migration Policy Instilute. Washington.

DOMENACH, $\mathrm{H}$.

(1996) "De la 'migratologie'..." In: Revue Européenne des Migrations Internationales, v. 12, n. 2. Poitiers.

HARZIG, C

(2003) "Immigration policies: a gendered historical comparison". In: MOROKVASIC. M.; EREL, U.; SHINOZAKI, K. (orgs.) Crossing Borders and shifting boundaries, v. 1, Oplanden.

MOROKVASIC, M.

(2003) "La mobilité transnacionale comme resource: le cas des migrants de l'Europe de I'Est". In: Cultures et Conflits, v. 32. Paris.

OLIVEIRA, T.

(1998) Uma fronteira para o por do sol. Universidade do Mato Grosso do Sul, Ed. UFMS, Campo Grande.

PESSAR, P.R.

(s/d) "The Linkage Between the household and workplace of dominican women in the U.S.". International Migration Review, v. XVIII, n. 4.

SILVA, S. A. da

(1997) Costurando Sonhos: Etnografia de um grupo de imigrantes bolivianos que trabalham no ramo da costura em São Paulo. São Paulo. Ed. Paulinas.

SOUCHAUD, S. e BAENINGER, R. (2008) Diferenciais da Imigração Boliviana em Corumbá: resultados da pesquisa de campo. Seminàrio Internacional de Estudos Fronteiriços. UFMS-MS.

SOUCHAUD, S. e FUSCO, W. (2007) Documentaçāo da pesquisa de campo Encuesta Corumbá. Disponivel em: www. nepo.unicamp.br 